This is the peer reviewed version of the following article: HERBST, P. and PRÜFER, J. (2016), FIRMS, NONPROFITS, AND COOPERATIVES: A THEORY OF ORGANIZATIONAL CHOICE. Annals of Public and Cooperative Economics, 87: 315-343. doi: 10.1111/apce.12130, which has been published in final form at http://onlinelibrary.wiley.com/wol1/doi/10.1111/apce.12130/full. This article may be used for non-commercial purposes in accordance With Wiley Terms and Conditions for self-archiving. 


\title{
Firms, Nonprofits, and Cooperatives: A Theory of Organizational Choice*
}

\author{
Patrick Herbst ${ }^{\dagger}$ \\ University of Stirling
}

\author{
Jens Prüfer $\ddagger$ \\ Tilburg University
}

December 21, 2015

\begin{abstract}
We formalize the difference between profit-maximizing firms, nonprofits, and cooperatives and identify optimal organizational choice in a model of quality provision. Firms provide lowest and nonprofits highest levels of quality. Efficiency, however, depends on the competitive environment, the decision making process among owners and technology. Firms are optimal when decision making costs are high. Else, firms are increasingly dominated by either nonprofits or cooperatives. Increased competition improves relative efficiency of firms and decreases relative efficiency of nonprofits.
\end{abstract}

JEL classification: L21, L31, D23

Keywords: Theory of the Firm, Nonprofits, Cooperatives, Organizational Choice, Organizational Change

*We are grateful to Eric van Damme, Mathias Erlei, Guido Friebel, Peter-J. Jost, Ulf von Lilienfeld-Toal, Pierre Koning, Uwe Walz, David Zetland, and a reviewer for comments and suggestions. Participants at the AEA Chicago, EARIE Amsterdam, EEA Vienna, GEABA Bielefeld, German Economic Association Bonn, ISNIE Barcelona, Summer School on Game Theory Bolzano and seminars in Frankfurt, Tilburg, Vallendar, and the CPB Den Haag also provided valuable comments.

${ }^{\dagger}$ Stirling Management School, Accounting and Finance Division, University of Stirling, Stirling, FK9 4LA, UK; email: patrick.herbst@stir.ac.uk.

¥TILEC and CentER, Department of Economics, Tilburg University; P.O. Box 90153; 5000 LE Tilburg, The Netherlands; e-mail: j.prufer@uvt.nl 


\section{Introduction}

An organization's form determines its economic success. Although organizational form appears fixed for many organizations, it can also change. In 2006, the New York Stock Exchange (NYSE) and Mastercard, two major financial institutions, converted from cooperatives to investor-owned firms. ${ }^{1}$ Visa, another major credit card operator, swiftly followed suit, completing its demutualization process with an IPO in 2008. These specific events continue the trend of organizational change in the financial sector (see the survey by Chaddad and Cook, 2004), retailing, and professional services. $^{2}$ On the other hand, the percentage of for-profit nursing homes in the United States has decreased by 23 percent between 1985 and 1995, while nonprofit-operated increased by 13.2 percent (see Chou, 2002). As there is no uniquely optimal organizational form, it is important to examine the pros and cons of each, especially in the light of the current trend to privatize formerly "essential" services (such as hospitals, prisons, or educational institutions) in many OECD countries.

What determines optimal organizational structure? We make three contributions towards an answer: First, we formalize the difference between profitmaximizing firms, nonprofits, and cooperatives and compare the efficiency of each in order to endogenize organizational choice. Second, we explain how nonprofits and cooperatives might exist - even with rational, self-interested consumers and without asymmetric information about product quality. Third, we examine the impact of outside competition on organizational change - one of the mostfrequently cited reasons for shifts in organizational structures. We compare efficiency among (i) purely profit maximizing firms; (ii) nonprofits pursuing a purely non-monetary objective; (iii) cooperatives whose members enjoy both monetary payoffs and a non-monetary benefit. We consider the case where each organization employs a manager, who can exert effort to produce a good with the quality level set by the organization's owners but has discretion with respect to pricing. The decision making process is costly whenever owners' goals are not perfectly homogenous. We also consider the interaction between the set of owner-members and organizational outcomes.

We derive the following main results. In equilibrium, there is a clear ranking of qualities provided: firms provide lowest levels and nonprofits highest levels of quality. Efficiency, however, depends on the cost of production and the cost of collective decision making. For high cost of collective decision making, a firm usually is the most efficient form. Yet, for lower levels of these costs, firms are

\footnotetext{
${ }^{1}$ The NYSE converted its organization via the acquisition of Archipelago in March 2006, while Mastercard made its IPO in May 2006.

${ }^{2}$ In the UK, for example, the "Clementi Report" initiated a (still ongoing) discussion about the pros and cons of investor ownership of law firms. See www.legal-services-review.org.uk/ and the reporting in The Economist, December 16th 2004, or in the business press (e.g. the Financial Times, December 16th and 20th 2004).
} 
increasingly dominated by either nonprofits or cooperatives (depending on the incremental cost of quality production). Using comparative statics, we show that increased competition improves the efficiency of firms vis-à-vis nonprofits and cooperatives, thus providing a potential reason for organizational change.

Recent analyses of financial exchange demutualization generally support the trade-offs developed in the paper (see Aggarwal, 2002; Steil, 2002; Aggarwal and Dahiya, 2006). These studies report that almost every financial exchange was organized as a mutual organization during some period of its existence. Its owners were financial intermediaries (broker-dealers) who consumed the good provided by the exchange (the trading platform) and used it to sell their services to other investors. Initially, all owners shared their interests in the exchange's quality of transaction services (liquidity, trade-related services and regulations). However, increased competition - due to financial and technological developments as well as financial de-regulation - affected members of exchanges in various ways: As a direct effect, new trading technologies offered some brokers alternative means to trade. Additionally, it forced exchanges to consider introducing new trading systems, often at the expense of traditional floor-trading. This lead to more heterogenous interests among the original members, with disagreement about business development particularly between large international banks and local specialists (Steil, 2002). Demutualization of exchanges was thus seen as an optimal organizational response to tougher competition and more costly internal decision-making processes.

We follow the literature on organizational choice that emphasizes the influence of organizational form on objectives. ${ }^{3}$ Glaeser and Shleifer (2001) analyze nonprofits and firms when noncontractible quality matters. The entrepreneur who chooses the nonprofit form produces high quality because he can consume dividends only as perks. Vlassopoulos (2009) extends Glaeser and Shleifer (2001) and finds that, when reputations can be sustained, the for-profit organizational form is always preferable in that setup. Therefore, Vlassopoulos concludes that the focus on contractual imperfections in the producer/consumer relationship alone cannot explain the variety of organizational forms observed empirically. This finding is reflected in our model by the assumption that the owners of an organization, who may also consume the product, can contract with the manager on the quality produced.

Malani, Philipson, and David (2003) compare the noncontractible quality model with alternative nonprofit models of altruism and worker cooperatives. They report that empirical studies comparing nonprofits and firms provide no clear ranking of the theoretical models with respect to their predictive power. Hart and Moore (1996) compare firms and cooperatives when monopoly pricing

\footnotetext{
${ }^{3}$ Note that this approach differs from the literature on organizational design that analyzes optimal internal structures for a given organizational form. See, for example, Athey and Roberts (2001) or Hart and Moore (2005).
} 
or skewness in members' preferences distort prices such that the first-best cannot be reached. They also find that firms are more competitive than cooperatives. In an analysis of partnerships, which are reminiscent of the cooperatives we model, Levin and Tadelis (2005) focus on the choice of partner quality. The authors show that partnerships are preferable in settings of high market power. Prüfer (2011) models duopoly competition between nonprofits in a model related to the one at hand. He shows that the owners' objective function has a strong impact on the welfare implications for mergers among nonprofits. Finally, Hart, Shleifer, and Vishny (1997) compare public and private firms in the provision of quality and cost efficiency.

In all these contributions, the different objectives implied by an organizational form affect the economic outcomes and highlight the trade-offs in organizational choice. However, none of them attempts to compare the performance of three organizational forms in a uniform framework that establishes a level playing field across forms. In our model, each type of organization is characterized by separation of ownership and control where the employed manager has some discretion in decision making and heterogenous owners have potentially conflicting interests.

In section 2 , we describe the three organizational forms in more detail and relate the definitions further to the literature. Section 3 outlines the model. In section 4, we compare equilibria and efficiency of the three organizational forms. Section 5 contains the effect of competition on organizational efficiency and thus choice. In section 6 , we discuss robustness and extensions before concluding in section 7 . All proofs are relegated to the appendix.

\section{Organizational Forms}

Within the property rights based theory of the firm, an organization is characterized by ownership over assets. Following this literature, we define ownership by residual rights of control here. ${ }^{4}$ Consequently, one of the crucial traits of any organization is the identity of its owners. The type of owners, combined with other restrictions and determinants of their action space, determines the nature of the organization's overall objective function. Hereafter, we characterize each organizational form in three dimensions: (i) Who holds the residual rights of control? (ii) Who owns the claims to any residual income? (iii) What is the objective function of the owners? Further questions to be asked for any organizational form are: Where does the organization obtain financing from? And how do (multiple) owners achieve a decision about the issues at hand (and at what cost)? We will discuss these issues in the following paragraphs. Table 1 in the appendix summarizes the major characteristics for all three organizational forms.

One important characteristic of every organization is the identity of its dominating group of stakeholders (Hansmann, 1996): workers, suppliers, consumers,

\footnotetext{
${ }^{4}$ See Grossman and Hart (1986) or Hart and Moore (1990).
} 
or investors. For expositional clarity and to be able to compare the performance of all three organizational forms on a level playing field, in our model we focus on the case where the organization is dominated by consumers. This is commensurate with assuming that each player has a positive - yet heterogenous - marginal valuation of product quality.

In the case of for-profit firms, the valuation of owners (investors) is sufficiently low such that they do not buy the product themselves, in equilibrium, and foresee this outcome. Consequently, we define an organization where owners de facto maximize solely their financial return on investment as a firm. ${ }^{5}$ These investors can be thought of as individuals using the organization's dividends to purchase other, unmodeled goods. Hence, in contrast to cooperatives and nonprofits, investor-owners de facto do not benefit from consuming the product produced by their firm. They hold both residual rights of income and control. Absent any other imperfections and due to the absence of a consumption goal, all shareholders of a firm pursue the same objective, that is maximizing firm profits. Our basic analysis will hence show that investors' interests are completely aligned, and thus any investor could decide on behalf of the other investors. All operational costs in a firm have to be covered by its (expected) retained earnings.

On the other side of the spectrum, an organization is defined as a nonprofit if its owners - henceforth called members - have a purely non-financial interest in the activity of the organization. By definition, members of a nonprofit, in contrast both to firms and cooperatives, forego all rights of residual income. Generally, these rights could rest with the members as non-monetary perquisites (see e.g. Glaeser and Shleifer, 2001), be transferred to a manager or other employees (in cash or in perquisites), or be transferred to some other charitable use. This ex ante waiver of residual income is captured by the term non-distribution constraint. ${ }^{6}$ Despite the absence of residual income rights, members may use their control rights to dismiss managers not complying with their duty. This managerial compliance could be assured either by delegation via a board of trustees or directly via the members' general meeting. ${ }^{7}$

The valuation of quality by nonprofit members can stem from their consump-

\footnotetext{
${ }^{5}$ Unlike Glaeser and Shleifer (2001), we exclude single-owner and owner-managed firms but focus on multiple ownership as this allows us to capture issues of collective decision making as a specific and important aspect of many ownership structures.

${ }^{6}$ We note that other authors allow nonprofits to distribute their profits to owners, be it directly (Lakdawalla and Philipson, 2006) or indirectly via price subsidies (Kuan, 2001). While relaxing the non-distribution constraint takes into account aspects of some real nonprofit organizations, we stick to the original constraint in order to highlight the generic characteristics of nonprofits.

${ }^{7}$ In any type of organization with dispersed multiple owners, a manager has some leeway. However, once the cost of (mis-)behavior are sufficiently high or issues at stake are sufficiently important, owners/members can be expected to interfere and to be actively involved in the decision making process. See O'Regan and Oster (2005) for empirical evidence on the behaviour of nonprofits' board members and executive directors.
} 
tion preferences, for instance, in the case of a church or a community center that is organized by and produces services for its members, or when the nonprofit is a trade association that produces services that are both determined and consumed by its member-firms. ${ }^{8}$ Alternatively, a nonprofit's owners could be workers of a charity or be working in a "care" industry, such as health care, child care, or care for the elderly (Francois, 2007). Such workers are often intrinsically motivated to produce goods or services with public goods characteristics and therefore value a high quality of production. ${ }^{9}$

Both of these interpretations can be captured by a model in which nonprofit owners have a valuation for quality. Although the natural focus of members of a nonprofit in a model of quality production is on quality (given that an alternative use of funds is ruled out by the non-distribution constraint), we show that there can still be disagreement among members about the preferred quality level. ${ }^{10} \mathrm{As}$ a consequence, it is the median member who effectively determines the quality level contained in the manager's employment contract. Finally, nonprofits may (and often do) receive financing from donations or membership fees, in addition to financing out of retained earnings. ${ }^{11}$

Cooperatives resemble firms regarding the ability to pay out dividends, but they also have elements of a nonprofit. We define an organization as a cooperative if its owners have a direct interest in the cooperative's activity (as consumers, in this paper) but also care about dividends. Hence, members of a cooperative hold both residual rights of income and control. Our results will show that this leads to disagreement among members. Similarly to the nonprofit case, the median member's preferences will be implemented. In general, members of a cooperative have both their expected consumer surplus and the organization's revenues to finance operations.

In the terminology of Hansmann (1996), our model analyzes the ability of the three organizational forms to overcome the costs of market contracting which arise from market power in setting price and quality. By assuming certain key features

\footnotetext{
${ }^{8}$ In this case, "non-financial interests" refer to the fact that association members have no direct pecuniary benefits from membership, in the form of dividends or increased share prices. Our definition does not preclude an indirect pecuniary interest, which is satisfied through the consumption of the nonprofit association's services, for instance lobbying. See Prüfer (2015) or Larrain and Prüfer (2015) for details.

${ }^{9}$ See Besley and Ghatak (2005), Francois (2003, 2007), and Delfgaauw and Dur (2007, 2008) for models, empirical analysis, and further examples.

${ }^{10}$ Notably, in a model with different focus, nonprofit owners may maximize another nonfinancial objective. For instance, Filistrucchi and Prüfer (2013) show that decision makers in church-affiliated German nonprofit hospitals make strategic decisions that can be traced back to the teachings of their respective religions.

${ }^{11}$ In the model, we assume donors and members to be identical. We use the term members in order to highlight their possession of residual rights of control. Our specification of nonprofits and its owners is equivalent to the nonprofit cooperative of Hart and Moore (1998) and is related to the commercial nonprofit of Hansmann (1996).
} 
distinguishing the organizations, we model the trade-off between several costs of ownership. On the one hand, all organizations face the same cost structure for the production of quality (mainly in the form of managerial effort costs). On the other hand, there are costs of ownership which differ between the organizational forms. In investor-owned firms and to a lesser extent in cooperatives, consumer surplus has less weight (relative to profits) in the decision making process of the owners than is socially desirable. In combination with market power, this leads to underprovision of quality. The reverse is true for nonprofits: due to the nondistribution constraint, consumer surplus is key in owners' decision making while profitability aspects are neglected. Hence, costly overprovision of quality results. Finally, if individual members' preferences for quality differ and goal alignment of the membership base is not achieved, an organization incurs extra costs of collective decision making. In our model, these costs reduce the benefits of cooperatives and nonprofits which potentially arise from a higher weighting of consumer surplus in the decision making process.

Costs of collective decision making are common in the organizational economics literature, as discussed broadly in Hansmann (1996). In this paper, we interpret them as costs of the decision making process (see Dow and Putterman, 2000; Dow, 2001, for examples of the costs incurred in worker cooperatives). These costs usually stem from the need of members to collect information prior to the decision making, and from the costs of attending meetings. Additionally, there is a set of costs arising in the decision making process when multiple issues are to be decided and voting cycles might occur (see Zusman, 1992). Costs of collective decision making usually increase in the heterogeneity of a cooperative's members (see Hansmann, 1996). Finally, apart from the direct costs of the decision making process, further costs can arise from influence activities in organizations (see Milgrom, 1988, for example).

\section{The Model}

\subsection{General Structure}

Market setting: Consider a market for a quality product supplied by a single organization and demanded by a set of consumers. In order to create a level playing field, all organizational forms face the same technology and production and sales processes.

Due to minimum efficient scale requirements (fixed set-up costs), no entry occurs and the quality $q \in[0,1]$ offered is identical for all consumers. At the same time, there exists an imperfectly substitutable product offered in an alternative market. This competitive fringe is characterized by the tuple $\left(p_{0}, q_{0}\right)$ where $p_{0}$ is the price of this good and $q_{0}$ denotes the quality equivalent of the substitute. We impose $1>q_{0}>p_{0} \geq 0$ in order to ensure that the substitute good is a relevant 
alternative. $^{12}$

Players: All players are risk-neutral. Demand for the good stems from a mass of consumers normalized to unity. While consumers appreciate quality, they differ in the degree they value it. Let

$$
v(p, q, \theta, y)=\max \{\psi(p, q, \theta), 0\}+y
$$

be a consumer's indirect utility, where $y$ denotes any monetary income and $\psi(p, q, \theta) \equiv \theta q-p$ is her net consumption utility, which depends on the quality $q \in[0,1]$ and the price $p$ of the good as well as her personal valuation of quality, $\theta$. The term $\theta q$ thus represents a consumer's willingness to pay for a good of quality $q$, which is assumed to be unaffected by potential dividend payments. ${ }^{13}$ Individual valuation of quality is private knowledge and distributed uniformly over $[0,1]$.

Irrespective of its form, an organization requires a manager who exerts personal effort to produce quality $q$. Let $e(q) \geq 0$ be the twice continuously differentiable effort cost function of the manager with standard convexity assumptions:

$$
e^{\prime}(q) \geq 0, \quad e^{\prime \prime}(q)>0 \quad \text { and } \quad e(q=0)=0
$$

We normalize all other production costs to zero. Apart from a potential wage income, the manager is able to appropriate a small fraction $\varepsilon>0$ of revenues for himself (e.g. via financial tunneling or non-monetary-perks). Hence, he maximizes the sum of wage income, diverted revenues and the cost of effort. Finally, we assume that the manager has an outside option of zero.

We further impose the following two conditions on the manager's marginal cost of effort:

$$
\begin{aligned}
e^{\prime}\left(q=q_{0}+p_{0}\right) & <\frac{1-p_{0}^{2}}{4 p_{0}^{2}} \\
e^{\prime}(q=1) & \geq \frac{3}{8}+\frac{p_{0}^{2}}{8\left(1-q_{0}\right)^{2}}
\end{aligned}
$$

The first assumption ensures that the organization analyzed here provides a quality superior to the fringe, while the second constraint ensures interior solutions.

\footnotetext{
${ }^{12}$ The parameters for the competitive fringe are exogenous and may not be affected directly by any player, including the social planner. We think of $\left(p_{0}, q_{0}\right)$ being influenced by the general environment and trends such as globalization or technological development.

${ }^{13}$ Consumers are thus assumed to have quasi-linear preferences with respect to the quality product and some composite good. Hence, dividends do not affect the purchasing decision of consumers. Alternatively, one could assume that consumers purchase a large set of goods and have further sources of income. Any dividend payments in our model would hence be split on the whole set of goods and can be considered negligible relative to the other income.
} 
Management is controlled by the organization's owners. These owners stem from either of two groups. First, they can be a set of financial investors who maximize dividend payments. Or, second, they can be a sub-set of the consumers in the market. Consumer-owners maximize their personal utility.

Finally, there is a benevolent social planner whose only aim is to maximize total surplus generated in the market. As in Easley and O'Hara (1983) or Hansmann (1996, p. 23), the focus in our paper is on organizational efficiency, measured in terms of welfare. For this reason, we introduce the social planner in order to ensure that the efficient organizational choice is made ex ante. The central trade-off of the model prevails as long as the agent in charge of choosing organizational form positively values both consumer and producer surplus - even with excessive weight put on either side of the market.

Contracting and decision making: We assume that the owners of an organization cannot contract on the price level the manager sets or on the profits of the organization. In order to be able to evaluate prices (or profits), it is not sufficient to observe the price level per se. Rather, it is necessary to understand the underlying costs of production because they influence whatever is deemed to be an appropriate price (or profit) level. To observe the true underlying costs, however, requires business expertise which only the manager has.

We could assume that product quality is not contractible, either. However, the special role of consumer-owners makes this assumption less plausible: as buyers of the good, they directly observe the good's features and are thus able to determine its quality. If they are not satisfied with the quality, they could refuse to prolong the manager's job contract even without verifiable quality. Thus, as a model shortcut, we directly assume that the owners may contract on the quality level to be chosen by the manager.

Given the contractual constraints, owners of an organization have to induce the manager to provide the desired quality (and thus personal effort). This is done by an incentive contract specifying quality and a corresponding wage structure $w(q)$. If owners' preferences concerning the specifics of the contract (the quality to be produced) are not perfectly aligned, they have to induce a decision by majority voting. In this case, the decision making process involves costs of collective decision making $D .{ }^{14}$ In order to restrict our attention to positive net profits for all organizations in equilibrium, we impose the following assumption: ${ }^{15}$

$$
e(q=1) \leq D+\frac{1}{4}\left(\frac{1-q_{0}+p_{0}}{1-q_{0}}\right)^{2}
$$

Organizational set-up: Owners' decisions during the set-up period (in $t=1$, see below) are influenced by expectations on the profits $\pi_{j}(p, q, w)$ of the organi-

\footnotetext{
${ }^{14}$ Under perfect goal alignment, decision making authority can be assigned to any owner.

${ }^{15}$ Section 6 discusses the implications of potentially negative operational profits.
} 
zations, where $j \in\{F, N, C\}$. By assumption (5), we ensure that the organization does not need to collect fees to finance operations. We also assume that individual ownership does not cause any disutility for investors nor for those consumers that expect to be buyers. For example, if consumers have to spend time in order to be active owners, this assumption implies that active ownership yields compensating benefits whenever owners anticipate that their time is spent on a product they will consume in the future.

Finally, we make two assumptions concerning the structure of the dividend payout in nonprofits and cooperatives. First, members of a nonprofit organization explicitly waive their rights to any residual income. Rather we assume that any income is transferred to some charitable organization not modeled explicitly. ${ }^{16}$ This is a common legal rule internationally and ensures a binding non-distribution constraint. Second, we assume the simplest dividend structure feasible for the cooperative: each member gets an equal share of total operating profits. However, members have to buy the good for being eligible to receive dividend payments. This common requirement generally ensures that individuals do not join the cooperative as members for purely financial reasons (as investors).

\subsection{Timing}

\section{Organizational set-up:}

$t=0$ The social planner chooses the organizational form. Investors or expected buyers join the organization as owners.

$t=1$ The owners specify the management contract. This is costless if all owners agree on the quality level to be specified. Otherwise, costs of $D$ are incurred to identify the median owner.

\section{Production and consumption period:}

$t=2$ The manager produces quality $q$, expands effort $e(q)$, and sets price $p$.

$t=3$ Consumers decide about purchasing the good (or its substitute). All payoffs (consumption utility, wage payments and dividend payments) are realized thereafter.

We solve this game by backward-induction to identify a subgame-perfect equilibrium.

\footnotetext{
${ }^{16}$ The nonprofit's earnings are thus preserved in the economy and still enter the social planner's total surplus calculation.
} 


\section{Organizational Performance}

\subsection{Model preliminaries}

Before analyzing the effects of the three different organizational forms, we derive some preliminary results relevant for all organizational forms. All proofs to subsequent lemmas and propositions are provided in the appendix.

Managerial price setting: Consider first the decisions of the manager in organization $j$ once the wage structure $w(q)$ is set. A consumer will purchase the good as long as $\psi(p, q, \theta) \geq \max \left\{\psi\left(p_{0}, q_{0}, \theta\right), 0\right\}$. Assuming that organization $j$ provides higher quality than the competitive fringe, total demand for the good is $1-\hat{\theta}$, where $\hat{\theta}$ denotes the marginal consumer who is indifferent between purchasing from organization $j$ and the competitive fringe: ${ }^{17}$

$$
\hat{\theta}=\frac{p-p_{0}}{q-q_{0}} .
$$

Faced with this demand structure, the manager faces the following optimization problem:

$$
\max _{p, q} u_{M}(p, q)+w(q)
$$

where $u_{M}(p, q)=\varepsilon p(1-\hat{\theta}(p, q))-e(q)$. As the utility $u_{M}$ is continuous in the price, we can derive the following optimal pricing rule and corresponding demand:

$$
p_{j}(q)=\frac{q-q_{0}+p_{0}}{2} \text { and } \quad \hat{\theta}_{j}(q)=\frac{1}{2}-\frac{p_{0}}{2\left(q-q_{0}\right)} .
$$

Given quality, the manager thus maximizes revenues (which equal operational profits) by setting a monopolistic price. The quality choice depends on the wage structure set by the owners.

Management contract: When writing the management contract conditional on quality, the owners of the organization take into account the manager's subsequent optimization problem (7). ${ }^{18}$ Given that the owners wish to implement a specific quality level $q_{j}$, they optimally choose the following wage structure:

$$
w(q)= \begin{cases}-u_{M}\left(p_{j}\left(q_{j}\right), q_{j}\right) & \text { if } q=q_{j} \\ -\phi & \text { if } q \neq q_{j}\end{cases}
$$

where $\phi$ is a fine large enough to deter the manager to set his preferred quality level. As $\varepsilon$ is supposed to be small, this fine need not be large. Given his

\footnotetext{
${ }^{17}$ The earlier condition (3) ensures that $q>q_{0}$ will be feasible in equilibrium.

${ }^{18}$ The ability of the owners to perfectly anticipate the price-setting behavior of the manager does not affect our subsequent results qualitatively.
} 
outside option of zero, the wage contract thus compensates the manager for his personal effort cost in producing quality $q_{j}$, taking into account his benefits from appropriated revenues. ${ }^{19}$ Hence, his final compensation will be $w_{j}=e\left(q_{j}\right)-$ $\varepsilon p_{j}\left(q_{j}\right)\left(1-\hat{\theta}\left(p_{j}, q_{j}\right)\right)$. Combining this result with (8) yields organizational profits of

$$
\begin{aligned}
\pi_{j}\left(q_{j}\right) & =(1-\varepsilon) p_{j}\left(q_{j}\right)\left(1-\hat{\theta}\left(p_{j}, q_{j}\right)\right)-w\left(q_{j}\right)-I_{j} D \\
& =\frac{\left(q_{j}-q_{0}+p_{0}\right)^{2}}{4\left(q_{j}-q_{0}\right)}-e\left(q_{j}\right)-I_{j} D
\end{aligned}
$$

where $I_{j}=1$ if costs of collective decision making have to be incurred, and $I_{j}=0$ otherwise. Equation (10) shows that revenue appropriation by the manager does not lower the organizational profits as it is accounted for in the wage structure. These results hold for any organizational form and create the level playing field for the subsequent derivation of organizational outcomes.

First-best and second-best solutions: As a last step before analyzing the organizational forms, we consider the optimal choice by the social planner. In the first-best setting, the social planner is able to determine quality and allocation of the product. Optimally, every consumer consumes the high quality product (marginal costs are zero). The first-best quality level then solves

$$
\max _{q} \int_{0}^{1}(\theta q) d \theta-e(q) \text {. }
$$

which either yields an interior solution with $e^{\prime}\left(q_{F B}\right)=1 / 2$ or results in $q_{F B}=1$, depending on the effort cost function.

More relevant for the subsequent analysis is the second-best solution. In the second-best setting, the social planner is the owner of the organization which implies that he may only contract with the manager on the quality to be provided. Thus, price setting and demand is as specified in (8). Generally, the total surplus created in the market as a function of $q_{j}$ is defined as the sum of consumer surplus and profits generated by organization $j$ as well as by the competitive fringe:

$$
T S_{j} \equiv \int_{\hat{\theta}_{j}}^{1}\left(\theta q_{j}-p_{j}\right) d \theta+\pi_{j}\left(q_{j}, \cdot\right)+\int_{\underline{\theta}}^{\hat{\theta}_{j}}\left(\theta q_{0}-p_{0}\right) d \theta+\int_{\underline{\theta}}^{\hat{\theta}_{j}} p_{0} d \theta
$$

where $\underline{\theta}=\frac{p_{0}}{q_{0}}$ defines the marginal consumer who is indifferent between buying from the outside option and not buying at all. Re-arranging (12) yields

$$
T S_{j}=\frac{3}{8} q_{j}-e\left(q_{j}\right)-p_{0}^{2}\left(\frac{1}{8\left(q_{j}-q_{0}\right)}+\frac{1}{2 q_{0}}\right)+\frac{q_{0}}{8}+\frac{p_{0}}{4}-I_{j} D .
$$

\footnotetext{
${ }^{19}$ An alternative, more practical contract would set the desired quality $q_{j}$ as a minimum level of quality required. As the manager in equilibrium always prefers to provide lower quality than required, the results from such a contract would be equivalent to the contract set in expression (9).
} 
Maximization of this surplus with respect to $q_{j}$ by the social planner defines the second-best quality level, $q_{S B}$ :

$$
e^{\prime}\left(q_{S B}\right)=\frac{3}{8}+\frac{p_{0}^{2}}{8\left(q_{S B}-q_{0}\right)^{2}}
$$

Condition (4) ensures that $q_{S B}<1$. The second-best quality level serves as a reference level for the subsequent analysis.

\section{$4.2 \quad$ Firms}

By definition, shareholders of a firm do not consume the good themselves (see section 2). Profit maximization is the single objective equally aspired by all shareholders. Given the expected market outcome as specified in equation (10), an investor thus aims to maximize his share $\delta_{F}$ of profits:

$$
\max _{q_{F}} \quad \delta_{F}\left(\frac{\left(q_{F}-q_{0}+p_{0}\right)^{2}}{4\left(q_{F}-q_{0}\right)}-e\left(q_{F}\right)-I_{F} D\right) .
$$

\section{Lemma 1 (Quality Provision of the Firm)}

(i) The firm offers product quality $q_{F}^{*} \equiv\left\{q \in\left(q_{0}+p_{0} ; 1\right] \mid e^{\prime}(q)=\frac{1}{4}-\frac{p_{0}^{2}}{4\left(q-q_{0}\right)^{2}}\right\}$.

(ii) Goal alignment among shareholders is perfect $\left(I_{F}=0\right)$.

The trade-off investors face is the increase in revenues from higher pricing versus higher costs of compensating the manager for his effort to produce higher quality. Firms hence provide goods of superior quality relative to the quality of the fringe as long as profits are non-negative. At the same time, it is obvious that a firm never has to bear costs of collective decision making: the pure focus on financial returns and the resulting goal alignment among shareholders is one of the key strengths of investor-owned firms, as it has been stressed in the literature for already some time (see Fama, 1978).

\subsection{Nonprofits}

Members of a nonprofit organization explicitly waive their rights to any residual income. Therefore, any member would prefer a product quality maximizing her indirect utility from the quality-price combination, taking into account the manager's decision as characterized in (8):

$$
\max _{q_{N}} \quad \theta q_{N}-\frac{q_{N}}{2}+\frac{q_{0}-p_{0}}{2} .
$$

The solution to this maximization problem is generally subject to the positive organizational profits; condition (5) ensures that this restriction is non-binding. 


\section{Lemma 2 (Quality Provision of the Nonprofit)}

(i) The nonprofit offers product quality of $q_{N}^{*} \equiv 1$.

(ii) There is no goal alignment among members $\left(I_{N}=1\right)$.

The result for the nonprofit in this lemma strongly depends on the nondistribution constraint. Without any potential dividend payments, owners simply care about their indirect utility from consuming the good. Hence, for the majority of owners (and thus the median owner) higher quality is always better. As a consequence, maximum quality $q_{N}^{*}=1$ is chosen. At the same time, owners with weaker preferences for quality would prefer lower levels of quality production as they suffer from price increase due to higher quality. Hence, disagreement among owners requires costly decision-making.

\subsection{Cooperatives}

In a cooperative, owners potentially get the best of two worlds: they are able to decide about the quality of the good to be provided (which they value themselves as consumers) and participate in residual profits. Let $\delta_{C} \geq 0$ be a member's profit share. Then a member solves:

$$
\max _{q_{C}} \quad \theta q_{C}-\frac{q_{C}}{2}+\frac{q_{0}-p_{0}}{2}+\delta_{C}\left(\frac{\left(q_{C}-q_{0}+p_{0}\right)^{2}}{\left(q_{C}-q_{0}\right) 4}-e(q)-I_{C} D\right)
$$

A member thus maximizes the sum of her indirect utility from purchase of the good and her share in the residual income (profits). In equilibrium, every consumer purchasing the cooperative's good will also become a member of the organization.

\section{Lemma 3 (Quality Provision of the Cooperative)}

(i) The cooperative offers product quality $q_{C}^{*} \equiv\left\{q \in\left(q_{0}+p_{0} ; 1\right] \mid e^{\prime}(q)=\frac{3}{8}-\frac{3 p_{0}^{2}}{8\left(q-q_{0}\right)^{2}}\right\}$.

(ii) There is no goal alignment among members $\left(I_{C}=1\right)$.

Members of the cooperative face the trade-off between choosing higher quality levels, which increases consumption utility at higher costs of inducing managerial effort, or inducing lower quality and thus increasing their dividend payout. Consequently, neither the maximum quality level of the nonprofit nor the profitmaximizing level of the firm are optimal for members. Additionally, the trade-off between consumption utility and dividends depends on individual preferences. Hence, members of the cooperative incur costs of collective decision making.

Summing up, we find a clear ranking in terms of quality provided in the market by the three forms of organization.

\section{Proposition 1 (Ranking of Qualities Provided)}

Given the definitions in lemmas 1 to 3 and equation (14), we have $q_{F}^{*}<q_{C}^{*} \leq$ $q_{S B} \leq q_{N}^{*}$. 
Nonprofit members, by waiving their rights to appropriate the residual income, only care about their individual consumer surplus. Consequently, they demand the maximum level of quality and neglect any inefficiencies arising from overspending on quality. This explains why nonprofits are often perceived to operate inefficiently and expensively. Nevertheless, overspending is completely in the interest of their members, as they exchange income rights for quality. The social planner, in contrast, trades off the benefits and costs (specifically the manager's effort cost) of quality.

On the other side, firms exclusively maximize monetary profits, thus producing too low a quality. Cooperatives, while being an organizational mix of firms and nonprofits, provide a level of quality that lies between the level of firms and the second-best level. The objective function of cooperative members contains both consumer surplus and producer surplus. Consequently, cooperatives even achieve the second-best quality level under certain circumstances. ${ }^{20}$ However, the presence of the competitive fringe (with $q_{0}>p_{0}>0$ ) leads the cooperative to sell to consumers with low quality preferences (consumers with $\theta<1 / 2$ ). As these consumers are also members, their preferences affect the quality-provision in the cooperative, yielding inefficiently low quality.

\subsection{Comparing Organizational Forms}

The preceding analysis has shown that the three organizational forms provide different levels of price-quality combinations. However, the quality level alone does not automatically determine which organization is efficient. To draw conclusions about the efficiency of an organization, total surpluses as in (13) have to be compared. We compare organizations pairwise and characterize the conditions under which each of them generates a higher total surplus.

\section{Proposition 2 (Organizational Efficiency)}

(i) Total surplus under nonprofit organization is higher than under firm organization (or equal to) if

$$
0 \leq D \leq \bar{D}_{N F} \equiv \frac{3}{8}+\frac{p_{0}^{2}}{8\left(q_{N}^{*}-q_{0}\right)\left(q_{F}^{*}-q_{0}\right)}-\frac{e\left(q_{N}^{*}\right)-e\left(q_{F}^{*}\right)}{q_{N}^{*}-q_{F}^{*}}
$$

is satisfied. Otherwise, firms generate higher total surplus.

(ii) Total surplus under cooperative organization is higher than under firm organization (or equal to) if

$$
0 \leq D \leq \bar{D}_{C F} \equiv \frac{3}{8}+\frac{p_{0}^{2}}{8\left(q_{C}^{*}-q_{0}\right)\left(q_{F}^{*}-q_{0}\right)}-\frac{e\left(q_{C}^{*}\right)-e\left(q_{F}^{*}\right)}{q_{C}^{*}-q_{F}^{*}} \geq 0
$$

\footnotetext{
${ }^{20}$ Cooperatives would produce second-best quality for $p_{0}=0$, that is under highest competitive pressure from the competitive fringe.
} 
is satisfied. Otherwise, firms generate higher total surplus.

(iii) Total surplus under nonprofit organization is higher than under cooperative organization (or equal to) if

$$
\frac{e\left(q_{N}^{*}\right)-e\left(q_{C}^{*}\right)}{q_{N}^{*}-q_{C}^{*}} \leq \frac{3}{8}+\frac{p_{0}^{2}}{8\left(q_{N}^{*}-q_{0}\right)\left(q_{C}^{*}-q_{0}\right)}
$$

is satisfied. Otherwise, cooperatives generate higher total surplus.

Since decision making in cooperatives and nonprofits implies extra costs of collective decision making, parts (i) and (ii) of proposition 2 depend on $D$. For sufficiently high costs of collective decision making, firms are always the preferred organizational form. In the pairwise comparisons, we find that cooperatives dominate firms as long as the costs of collective decision making are sufficiently low. This result is intuitive since we have $q_{F}^{*}<q_{C}^{*} \leq q_{S B}$ : only large realizations of $D$ can make cooperatives less efficient than firms. Therefore, if collective decision making is not very costly - for example because of low heterogeneity of owners - cooperatives combine the best of two worlds by maximizing a combination of consumer surplus and owners' profits.

As $q_{F}^{*}<q_{S B}<q_{N}^{*}$, it is not so clear whether firms or nonprofits are more efficient, even if decision making costs in nonprofits are low. In addition to low $D$, superiority of nonprofit relative to firm organization requires that the cost increases from raising quality from firm level (inefficiently low) to nonprofit level (excessively high) is sufficiently low.

Comparing nonprofit with cooperative organization, cooperatives provide lower quality but generate higher profits as the compensation of managerial effort is less costly. Nonprofits, on the other hand, provide higher quality at the expense of higher effort cost. The LHS of condition (20) measures the additional costs incurred from increasing the quality level of the cooperative to nonprofit level relative to the quality change. Intuitively, if the excess quality provision by the nonprofit is less costly, high quality production by the manager is affordable and nonprofit organization dominates cooperative organization. If high effort is instead overly costly, it is more efficient to let the cooperative produce the good.

All three pairwise efficiency comparisons depend on the ratio of cost and quality differences. An increase (decrease) in convexity of the effort cost function increases (decreases) this ratio, and hence affects the relative efficiency of the three organizations. This effect is used in figure 1 which illustrates the efficiency comparisons of proposition 2. Using a numerical example, we plot the critical levels of the costs of collective decision making against the convexity of effort cost. $^{21}$ For decision making cost levels above the line $\bar{D}_{C F}$, firms produce higher total surplus than cooperatives. Similarly, for levels above the line $\bar{D}_{N F}$, firms dominate nonprofit organizations. With rising costs $D$ the set of parameters

\footnotetext{
${ }^{21}$ For details on the numerical example see appendix A.10.
} 
Figure 1: Optimal Organizational Forms

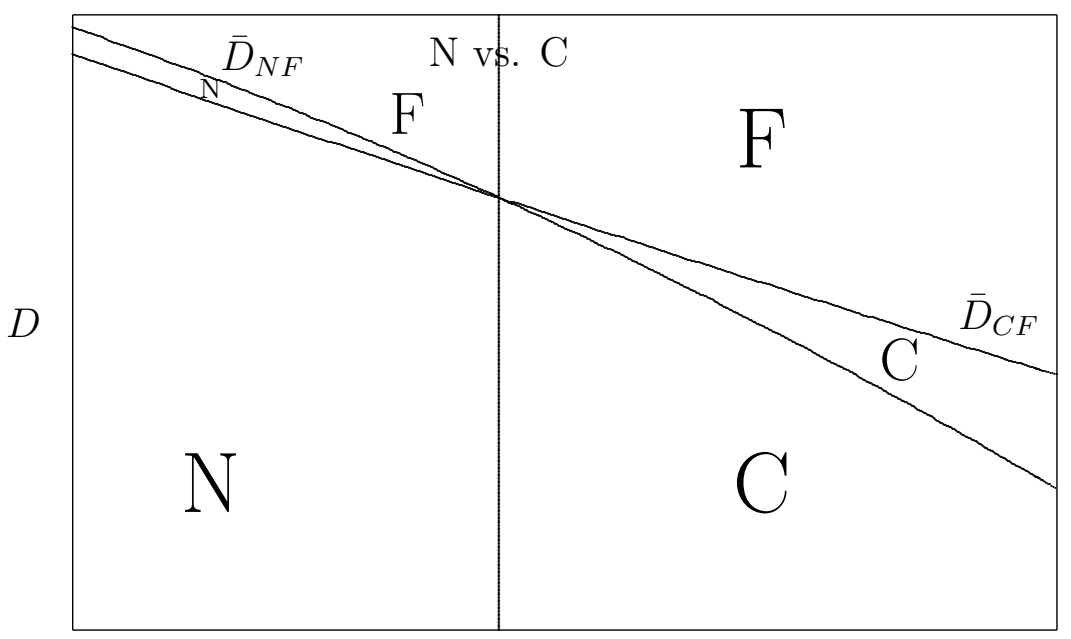

Convexity of effort cost

Note: Numerical example with $e(q)=x \cdot q^{2} / 4$, where $x$ measures the convexity of effort cost. Further details are provided in appendix A.10.

where either cooperatives or nonprofits are preferable shrinks and becomes empty for sufficiently high levels. For very low cost levels, cooperatives or nonprofits are efficient, depending on the convexity of effort (with the vertical line giving the threshold level). The figure also highlights which organization is most efficient in the six parameter sets defined by the three plotted lines.

Proposition 2 and figure 1 specify the main results of the analysis so far. The social planner will choose the most efficient organizational form in $t=0$, which depends on specific parameters of the exogenous variables. This strategy together with lemmas 1 to 3 and managerial pricing as in (8) characterizes the subgame-perfect equilibrium.

\section{Changes in Organizational Efficiency}

What happens to relative organizational efficiency if the pressure exerted by the competitive fringe is increased? Or, alternatively, do we expect organizational persistence in a changing competitive environment (due to, for example, globalization or technological progress)? To approach this issue, we now consider how our previous results are affected by changes in the competitive fringe.

Note first that in $t=2$, the decisions of the organization's manager determine the market outcome, described by $p_{j}^{*}, \hat{\theta}_{j}^{*}$ and $\pi_{j}^{*}$ in (8) and (10). The comparative statics of these variables with respect to the price $p_{0}$ of the substitute good are intuitive: A decrease in $p_{0}$ makes the substitute good more attractive, thus 
taking away market share from the organization. Although this is countered by the manager decreasing the price, the overall effect on market share and profits remains negative. Formally, $\frac{d p_{j}^{*}}{d p_{0}}>0, \frac{d \hat{\theta}_{j}^{*}}{d p_{0}}<0$ and $\frac{d \pi_{j}}{d p_{0}}>0$.

A change in the quality equivalent $q_{0}$ of the substitute good, however, has slightly different effects: a more attractive substitute good (higher $q_{0}$ ) is countered by a lower price which leads to a higher market share than before for the organization, formally $\frac{d p_{j}^{*}}{d q_{0}}<0$ and $\frac{d \hat{\theta}_{j}^{*}}{d q_{0}} \leq 0$. The latter result appears counterintuitive and is due to the increased elasticity of demand. As the substitute good's quality rises, not only its attractiveness rises but also the vertical differentiation between the two markets decreases. Hence, consumers react more sensitively to price differences. For this reason, the lowering of $p_{j}^{*}$ actually leads to a higher level of sales than before. Overall however, profits still decrease: $\left(\frac{d \pi_{j}}{d q_{0}}<0\right)$. As the effect of changes in $q_{0}$ are rather specific to our modelling structure, we will focus on changes in the price level $p_{0}$ of the competitive fringe in our following analysis. $^{22}$

\subsection{Changes in Quality}

Optimal quality levels $q_{j}^{*}$ chosen in $t=1$ are also affected by changes in the competitive fringe. We now analyze how the price $p_{0}$ affects quality, and use a decrease in this price (tougher competitive environment) for interpretation. This might be due to process innovations in the market segment producing the closest substitute which decreases marginal costs and thus lowers the price level.

\section{Lemma 4 (Changes in Quality)}

A more competitive substitute good (a decrease in $p_{0}$ ) has the following effects:

(i) the quality of the nonprofit remains unaffected, $\frac{d q_{N}^{*}}{d p_{0}}=0$;

(ii) the quality of the firm increases, $\frac{d q_{F}^{*}}{d p_{0}} \leq 0$;

(iii) the quality of the cooperative increases, $\frac{d q_{C}^{*}}{d p_{0}} \leq 0$.

The intuition for this lemma is rather simple. Owners in firms and cooperatives positively value dividends and therefore counter the negative effect of a more attractive competitive fringe by further differentiating their product quality from the substitute quality. Hence, competition induces them to increase the quality on offer (competition effect). For the cooperative, there is an additional membership effect: A tougher competitive environment implies that the cooperative loses

\footnotetext{
${ }^{22}$ In the standard models of vertical differentiation, prices and quality levels are strategic choices of all players. As we disregard strategic interaction between the organization and the competitive fringe, focussing on changes in the exogenous price $p_{0}$ (as a proxy for changes in competitiveness) is appropriate here. For completeness, we report the results for changes in $q_{0}$ in the appendix as well.
} 
some buyers and hence members. As this change shifts the preferences of the median member upwards, there is an additional positive effect on the quality. Since nonprofits already produce the maximum quality achievable, they can only react to increased competitive pressure by cutting the price. Accordingly, since $q_{N}$ in (8) remains constant, nonprofits will lose a comparatively higher market share than cooperatives or firms. The latter effect may be a reason for the common perception of nonprofits being inflexible in adjusting to market changes.

\section{Lemma 5 (Relative Changes in Quality)}

A more competitive substitute good (a decrease in $p_{0}$ ) has the following effects:

(i) firms increase the level of quality by more than nonprofits $d o, \frac{d q_{N}^{*}}{d p_{0}}-\frac{d q_{F}^{*}}{d p_{0}} \geq 0$;

(ii) cooperatives increase the level of quality by more than nonprofits $d o, \frac{d q_{N}^{*}}{d p_{0}}-$ $\frac{d q_{C}^{*}}{d p_{0}} \geq 0$

(iii) firms increase the level of quality by more than cooperatives $d o, \frac{d q_{C}^{*}}{d p_{0}}-\frac{d q_{F}^{*}}{d p_{0}} \geq 0$, if and only if

$$
2 e^{\prime \prime}\left(q_{C}^{*}\right)\left(q_{C}^{*}-q_{0}\right)^{2}-3 e^{\prime \prime}\left(q_{F}^{*}\right)\left(q_{F}^{*}-q_{0}\right)^{2} \geq p_{0}^{2} \frac{q_{F}^{*}-q_{C}^{*}-0.5\left(q_{C}^{*}-q_{0}\right)}{\left(q_{C}^{*}-q_{0}\right)\left(q_{F}^{*}-q_{0}\right)} .
$$

The comparisons of quality changes of the nonprofit with the firm or the cooperative are trivial: nonprofits do not alter the quality level in the light of increased competition from the fringe, but firms and cooperatives do so. Therefore, firms and cooperatives reduce the quality lead of the nonprofit by increasing their own quality levels.

The comparison of changes in qualities for cooperative and firm is less obvious. Condition (21) illustrates that the form of the effort cost function plays an important role. If its curvature and the quality differences between firm and cooperative are large enough, then the firm will react more strongly to changes in the competitive environment than the cooperative. If condition (21) is not satisfied, then the cooperative's quality lead over the firm increases under a more competitive environment.

\subsection{Changes in Efficiency}

We have characterized all preliminary results needed to analyze changes in the optimality of organizational forms. We now present our central result on the impact of competition on the efficiency of the three organizational forms.

\section{Proposition 3 (Changes in Organizational Efficiency)}

A more competitive substitute good (a decrease in $p_{0}$ ) has the following effects:

(i) total surplus under firm organization relative to nonprofit organization increases, $\frac{d\left(T S_{N}-T S_{F}\right)}{d p_{0}} \geq 0$; 
(ii) total surplus under cooperative organization relative to nonprofit organization increases, $\frac{d\left(T S_{N}-T S_{C}\right)}{d p_{0}} \geq 0$;

(iii) total surplus under firm organization relative to cooperative organization increases, $\frac{d\left(T S_{C}-T S_{F}\right)}{d p_{0}} \geq 0$, if condition (21) in lemma 5 is satisfied.

The total surplus generated by an organizational form directly depends on the position of its quality level relative to the second-best quality level. As specified in proposition $1, q_{F}^{*}<q_{C}^{*} \leq q_{S B}$, while $q_{N}^{*}>q_{S B}$. Both firms and cooperatives react to increased outside competition by increasing their quality levels, thus reducing inefficient underprovision of quality. Nonprofit quality, on the other side, is not affected by outside competition as nonprofit members only care about their utility from consumption. This explains why nonprofits lose relative to firms and cooperatives when competition gets tougher, as emphasized in parts (i) and (ii) of proposition 3.

Whether firms or cooperatives become more efficient when outside competition is increased depends on the relative adjustment of their quality levels towards $q_{S B}$. If firms adapt to competition more strongly than cooperatives, they also gain in terms of total surplus under higher competition. ${ }^{23}$

Figure 2: Changes in Organizational Efficiency

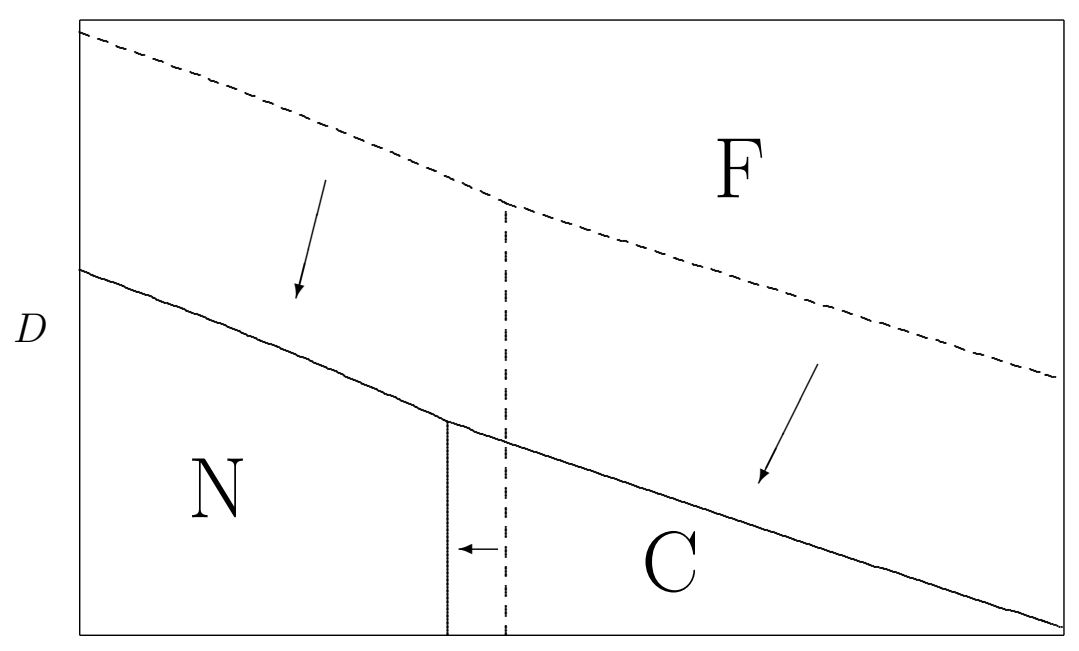

Convexity of effort cost

Note: Numerical example with $e(q)=x \cdot q^{2} / 4$, where $x$ measures the convexity of effort cost. Further details are provided in appendix A.10.

Figure 2 illustrates the efficiency comparisons of proposition 3. Based on the numerical example of figure 1, figure 2 shows how the set of parameters where

\footnotetext{
${ }^{23}$ In numerical simulations of the model, the increase in total surplus under firm organization always exceeded the increase under cooperative organization for various effort cost functions (see appendix A.10).
} 
either of the organizational forms is optimal changes under competition. ${ }^{24}$ The dashed lines replicate the static efficiency comparison of figure 1. The solid lines show the new optimal organizational choice if outside competition has increased. In the case illustrated in the figure, firms become more efficient relative to both nonprofits and cooperatives. Similarly, nonprofits lose against both firms and cooperatives, while cooperatives lose against firms but gain relative to nonprofits.

Overall, our results provide empirical predictions about observed organizational forms in different market environments. Differences in the degree of competition across markets translate into different organizational structures, with firms more prevalent in more competitive markets. Moreover, our results can also be used to explain changes in organizational forms over time. As markets become more competitive, we would predict an increase in the provision of goods by firms, rather than nonprofits or cooperatives. Such changes in organizational form might be induced by organizations actually being converted into new forms (as witnessed in the financial sector, see the initial credit card and stock exchange examples). Alternatively, these changes might be more gradual, driven by the demise of old, less efficient organizations and the creation and entry of new organizations. ${ }^{25}$

\section{Discussion and Extensions}

Operational losses, organizational existence, and membership fees: We assumed throughout the previous analysis that profits of all organizations are nonnegative (see (5)). We will now argue that the results of our model are robust even if the revenues of an organization are too low to finance its operations. In order to do so, we introduce fixed $\operatorname{costs} M$ of operations which any organization incurs. We then look at the effect of an increase in these costs on our results in terms of relative efficiency of the organizations.

For firms, an increase in fixed costs such that profits turn negative has straightforward effects: firms with negative profits will be closed down by its owners as investors solely care about financial returns. As long as a firm can exist, it will provide the quality level $q_{F}^{*}$ described in lemma 1 .

Nonprofits are the organizational form whose owners, by definition, care least about profits. If a nonprofit's existence is threatened, the social planner may start to levy a fee in order to finance operations. However, the ability of the social planner to collect membership fees from any organization's owners is restricted by private knowledge of individual preferences for quality, $\theta$. Nevertheless, the literature on mechanism design has shown that one can induce agents to reveal

\footnotetext{
${ }^{24}$ See appendix A.10 for more details on the numerical example.

${ }^{25}$ We are very grateful to a reviewer for pointing out this aspect of organizational change via the creation of new entities.
} 
their privately observable preferences. ${ }^{26}$ Assuming that the social planner is able to collect a fee from any consumer with preferences for quality above some threshold level, levying such a fee would affect the set of owners by driving the marginal owner $\tilde{\theta}_{N}$ upwards. Although this does not affect the equilibrium quality level of $q_{N}^{*}=1$, it may improve organizational efficiency by establishing goal alignment among members: if the marginal member has $\theta \geq 1 / 2$, there is no more disagreement among members about the quality. Consequently, costs of collective decision making are not incurred anymore.

The case of cooperatives is more complex. When profits turn negative, the social planner may levy a fee, similarly to the case of the nonprofit. The marginal owner $\tilde{\theta}_{C}$ would move upwards, as would the median owner. Initially, the equilibrium quality level $q_{C}^{*}$ would hence increase, and so would the price $p_{C}^{*}$ and the marginal buyer $\hat{\theta}_{C}$. Thus, apart from a fee income effect, levying this fee would entail a membership effect and a revenue effect, the aggregate effect of which on a cooperative's income does not have a clear-cut sign. ${ }^{27}$ Despite increased quality, the relative position of $q_{C}^{*}$, however, would not change as the upper bound on $q_{C}^{*}$ is still $q_{S B}$ (proposition 1 remains valid). Note, nevertheless, that a tighter budget can, under certain circumstances, increase the efficiency of a cooperative.

Generally, if losses in any organizational form are sufficiently high, it will not be able to exist. The de facto efficient form can thus differ from the theoretically efficient form characterized in proposition 2. Alternatively, if an organizational form is found to be efficient for specific parameter realizations but incurs negative profits, the social planner (as a government) may decide to finance it via lumpsum transfers. This can be interpreted as creating a kind of public organization, a topic that is of high importance in itself (not least because of the interaction between the public financier and the formal, private owners) but not the focus of our analysis. ${ }^{28}$

Managerial altruism: In the analysis, the manager only incurred costs from producing higher quality. However, one can argue that often employees and management derive some benefits from higher quality production as well (see Glaeser and Shleifer, 2001, for example). Assume that a manager derives a personal benefit $b(q) \geq 0$ from producing quality $q$, where $0 \leq b^{\prime}(q) \leq e^{\prime}(q)$. Given a zero outside option wage and a quality level $q$, the wage of a manager can thus

\footnotetext{
${ }^{26}$ See Fudenberg and Tirole (1991), chapter 7 . In contrast to the literature on the private provision of public goods (Bergstrom, Blume, and Varian, 1986; Bilodeau and Slivinski, 1997), consumers have zero marginal effect on the good's provision in our framework.

${ }^{27}$ The relation between the marginal owner and quality is actually non-monotonic. Once the marginal owner surpasses $\theta=1 / 2$, quality and price actually decrease in $\tilde{\theta}_{C}$. Hence, from an efficiency perspective, the membership effect (increasing $\tilde{\theta}_{C}$ ) can both reduce inefficient inclusion (if $\tilde{\theta}_{C}<1 / 2$ ) or create inefficient exclusion (if $\tilde{\theta}_{C} \geq 1 / 2$ ).

${ }^{28}$ Refer to Hart et al. (1997), Besley and Ghatak (2001) or DeWenter and Malatesta (2001) for related literature.
} 
be reduced by the size of the personal benefit. Hence, cooperatives and firms would provide higher qualities, and nonprofits would be able to provide maximum quality at lower costs. Qualitatively, however, altruism does not change our results. $^{29}$

\section{Conclusion}

This paper highlights some key differences between firms, nonprofits, and cooperatives, where each of these organizations is governed by economic principles and rational decision making. The different organizational structures and members' objective functions lead to different costs of ownership and thus affect organizational efficiency. The final efficiency trade-off then depends on the competitive environment, the decision making process and technology.

In the static efficiency comparison, firms are the optimal organizational form when costs of collective decision making are sufficiently high - despite the fact that they provide an inefficiently low quality level. In other words, firms are a low-cost means to produce quality as they offer the benefits of a straightforward organizational form where goal alignment is easily ensured. In contrast, both nonprofits and cooperatives suffer from disagreement among members and thus from costly decision making.

Quite opposite to firms, nonprofits serve as a means to commit to the production of high quality due to the lack of alternative usage of an organization's profits. As the quality level produced under nonprofit organization is inefficiently high, it only dominates the cooperative forms as long as the costs of raising quality (by inducing additional managerial effort) is low.

Lastly, members of a cooperative are concerned with both operational profits as well as (their own) consumer surplus. In an environment with imperfectly competitive markets, the overall objective function in a cooperative most closely resembles the objective function of a social planner. The drawback of this more complex objective function lies in the costs of collective decision making if the set of owners is heterogenous. Choice of the cooperative form thus requires low costs of decision making, for example due to a sufficiently low number of members who can coordinate easily or due to a sufficiently homogeneous membership base.

Apart from the static efficiency trade-off, this paper also considers how changes in the market environment affect the efficiency of the three organizational forms. Increases in competition have a disciplining effect on both firms and cooperatives: in order to compensate for lower demand, both organizational forms adjust the

\footnotetext{
${ }^{29}$ This result relates to the literature on objectives of owners and managers in nonprofits. Note that our focus is on the level playing field among organizational forms, so we explicitly exclude potential self-selection effects of managers of different types to different organizational forms (see e.g. Besley and Ghatak, 2005). Francois (2003) provides another approach by recruiting managers from the set of consumers.
} 
quality offered upwards. This implies that both organizations will be preferable to the nonprofit form more often. While the net effect on organizational efficiency may be ambiguous when cooperatives and firms are compared, our results suggest that, for standard technologies, firms will react more strongly to competitive pressure.

Although our model's results still await rigorous empirical testing, anecdotal evidence from studies of demutualization and from the statements made in the wake of the NYSE, Mastercard and Visa announcements suggests that competition plays an important role in organizational changes. Moreover, analyses of financial exchanges' conversion additionally highlight the role of internal decision making processes:

But, as markets became more sophisticated, the interests of various member groups began to diverge, causing tremendous strain in the governance and decision-making process of financial exchanges. (Aggarwal and Dahiya, 2006, p. 99)

In the terminology of our model, tougher competition and higher costs of collective decision making are a key feature of exchanges' environment today. The observed reaction by many exchanges, conversion to investor-owned firms, accord well with our model's predictions. 


\section{References}

Aggarwal, R. (2002). Demutualization and corporate governance of stock exchanges. Journal of Applied Corporate Finance 15(1), 105-113.

Aggarwal, R. and S. Dahiya (2006). Demutualization and public offerings of financial exchanges. Journal of Applied Corporate Finance 18(3), 96-106.

Athey, S. and J. Roberts (2001). Organizational design: Decision rights and incentive contracts. American Economic Review 91(2), 200-205.

Bergstrom, T., L. Blume, and H. Varian (1986). On the private provision of public goods. Journal of Public Economics 29, 25-49.

Besley, T. and M. Ghatak (2001). Government versus private ownership of public goods. Quarterly Journal of Economics 116(4), 1343-72.

Besley, T. and M. Ghatak (2005). Competition and incentives with motivated agents. American Economic Review 95(3), 616-36.

Bilodeau, M. and A. Slivinski (1997). Rival charities. Journal of Public Economics $66,449-467$.

Chaddad, F. R. and M. L. Cook (2004). The economics of organization structure changes: A US perspective on demutualization. Annals of Public and Cooperative Economics 75(4), 575-94.

Chou, S.-Y. (2002). Asymmetric information, ownership and quality of care: An empirical analysis of nursing homes. Journal of Health Economics 21(2), 293-311.

Delfgaauw, J. and R. Dur (2007). Signaling and screening of workers' motivation. Journal of Economic Behavior and Organization 62(4), 605-624.

Delfgaauw, J. and R. Dur (2008). Incentives and workers' motivation in the public sector. The Economic Journal 118(525), 171-191.

DeWenter, K. L. and P. H. Malatesta (2001). State-owned and privately owned firms: An empirical analysis of profitability, leverage, and labor intensity. American Economic Review 91(1), 320-34.

Dow, G. K. (2001). Allocating control over firms: Stock markets versus membership markets. Review of Industrial Organization 18, 201-218.

Dow, G. K. and L. Putterman (2000). Why capital suppliers (usually) hire workers: What we know and what we need to know. Journal of Economic Behavior and Organization 43, 319-336. 
Easley, D. and M. O'Hara (1983). The economic role of the nonprofit firm. Bell Journal of Economics 14(2), 531-538.

Fama, E. F. (1978). The effects of a firm's investment and financing decisions on the welfare of its security holders. American Economic Review 68(3), 272-84.

Filistrucchi, L. and J. Prüfer (2013). Faithful strategies: How religion shapes nonprofit management. CentER Discussion Paper No. 2013-052.

Francois, P. (2003). Not-for-profit provision of public services. Economic Journal 113(486), C53-61.

Francois, P. (2007). Making a difference. The RAND Journal of Economics 38(3), $714-732$.

Fudenberg, D. and J. Tirole (1991). Game Theory. Cambridge, MA.

Glaeser, E. L. and A. Shleifer (2001). Not-for-profits entrepreneurs. Journal of Public Economics 81, 99-115.

Grossman, S. J. and O. D. Hart (1986). The costs and benefits of ownership: A theory of vertical and lateral integration. Journal of Political Economy 94, $235-259$.

Hansmann, H. (1996). The Ownership of Enterprise. Cambridge, MA.

Hart, O. and J. Moore (1990). Property rights and the nature of the firm. Journal of Political Economy 98, 1119-1158.

Hart, O. and J. Moore (1996). The governance of exchanges: Members' cooperatives versus outside ownership. Oxford Review of Economic Policy 12, 53-69.

Hart, O. and J. Moore (1998). Cooperatives vs. outside ownership. National Bureau of Economic Research Working Paper 6421.

Hart, O. and J. Moore (2005). On the design of hierarchies: Coordination versus specialization. Journal of Political Economy 113(4), 675-702.

Hart, O., A. Shleifer, and R. W. Vishny (1997). The proper scope of government: Theory and an application to prisons. Quarterly Journal of Economics 112(4), $1127-61$.

Kuan, J. (2001). The phantom profits of the opera: Nonprofit ownership in the arts as a make-buy decision. Journal of Law, Economics, and Organization 17, $507-520$.

Lakdawalla, D. and T. Philipson (2006). The nonprofit sector and industry performance. Journal of Public Economics 90(8-9), 1681-1698. 
Larrain, M. and J. Prüfer (2015). Trade associations, lobbying, and endogenous institutions. Journal of Legal Analysis forthcoming.

Levin, J. and S. Tadelis (2005). Profit sharing and the role of professional partnerships. Quarterly Journal of Economics 120(1), 131-71.

Malani, A., T. Philipson, and G. David (2003). Theories of firm behavior in the nonprofit sector: A synthesis and empirical evaluation. In E. L. Glaeser (Ed.), The governance of not-for-profit organizations, pp. 181-215. U Chicago: University of Chicago Press.

Milgrom, P. R. (1988). Employment contracts, influence activities, and efficient organization design. Journal of Political Economy 96, 42-60.

O'Regan, K. and S. M. Oster (2005). Does the structure and composition of the board matter? The case of nonprofit organizations. Journal of Law, Economics, and Organization 21(1), 205-27.

Prüfer, J. (2011). Competition and mergers among nonprofits. Journal of Competition Law and Economics 7, 69-92.

Prüfer, J. (2015). Business associations and private ordering. Journal of Law, Economics, and Organization forthcoming.

Steil, B. (2002). Changes in the ownership and governance of securities exchanges: Causes and consequences. Brookings-Wharton Papers on Financial Services, $61-82$.

Vlassopoulos, M. (2009). Quality, reputation and the choice of organizational form. Journal of Economic Behavior and Organization 71, 515-527.

Zusman, P. (1992). Constitutional selection of collective-choice rules in a cooperative enterprise. Journal of Economic Behavior and Organization 17, 353-362. 


\section{A Appendix}

\section{A.1 Organizational Forms}

\begin{tabular}{llllr}
\hline & Firm & Cooperative & Nonprofit \\
\hline \hline $\begin{array}{l}\text { Residual Rights } \\
\text { of Control }\end{array}$ & Shareholders & Members & $\begin{array}{l}\text { Members } \\
\text { (Donors) }\end{array}$ \\
\hline $\begin{array}{l}\text { Claim } \\
\begin{array}{l}\text { Residual } \\
\text { come }\end{array}\end{array}$ & In- & Shareholders & $\begin{array}{l}\text { (Consuming) } \\
\text { Members }\end{array}$ & $\begin{array}{l}\text { Donated to Char- } \\
\text { ity }\end{array}$ \\
\hline Financing & Revenues & Revenues & & \\
& & Membership Fees & Membership Fees \\
\hline $\begin{array}{l}\text { Membership } \\
\text { Calculus }\end{array}$ & Dividend & Dividend + Con- & Consumer Sur- \\
\hline
\end{tabular}

Table 1: Major organizational differences

\section{A.2 Proof of Lemma 1}

(i): The assumptions on the effort cost function in (2) and (4) ensure existence of an interior solution strictly between zero and one. The first-order condition to (15) is then

$$
\frac{1}{4}-\frac{p_{0}^{2}}{4\left(q_{F}-q_{0}\right)^{2}}-e^{\prime}\left(q_{F}\right)=0
$$

which defines $q_{F}^{*}$. The requirement $q_{F}^{*}>q_{0}+p_{0}$ is fulfilled whenever

$$
e^{\prime}\left(q_{0}+p_{0}\right)<\frac{1}{4}-\frac{p_{0}^{2}}{4\left(q_{F}^{*}-q_{0}\right)^{2}} \geq 0
$$

is satisfied. Second-order conditions additionally require

$$
S O C_{F} \equiv \frac{p_{0}^{2}}{2\left(q_{F}^{*}-q_{0}\right)^{3}}-e^{\prime \prime}\left(q_{F}^{*}\right)<0 .
$$

(ii) follows from the absence of $\theta$ in the first-order condition.

Q.E.D.

\section{A.3 Proof of Lemma 2}

(i): The first-order derivative of a consumer/owner's objective function is $\theta-\frac{1}{2}$. This is strictly positive for $\theta>\frac{1}{2}$ and strictly negative for $\theta<\frac{1}{2}$. Hence, there are conflicting interests, such that a decision by majority voting is required. Let $\tilde{\theta}_{N}$ denote the marginal member of the nonprofit such $\theta \in[\tilde{\theta}, 1]$ for all members. 
Even under maximum ownership (marginal member equals marginal consumer, $\tilde{\theta}_{N}=\hat{\theta}_{N}>0$ ), the median owner's preference parameter $\theta$ is always above $\frac{1}{2}$. Hence, maximum quality $q_{N}^{*}=1$ is always chosen.

(ii): While the quality $q_{N}^{*}$ offered is unaffected by the position of the marginal member, $\tilde{\theta}_{N}<\frac{1}{2}$ implies that costs of collective decision making $D$ have to be incurred.

Q.E.D.

\section{A.4 Proof of Lemma 3}

(i): From (17) the first-order condition for a member translates into

$$
e^{\prime}\left(q_{C}\right)=\frac{1}{4}-\frac{p_{0}^{2}}{4\left(q_{C}-q_{0}\right)^{2}}+\left(\theta-\frac{1}{2}\right) \frac{1}{\delta_{C}} .
$$

Hence, the individually optimal quality levels differ for different $\theta$; it is impossible to find two members with distinct preferences $\theta$ who would prefer the same level of quality. Consequently, collective decision making by a majority vote leads to the outcome preferred by the median member.

In order to determine the median member, let $\tilde{\theta}_{C}$ denote the marginal member of the cooperative such that every consumer with $\theta \geq \tilde{\theta}_{C}$ joins the cooperative as a member. As a result, a member's profit share is $\delta_{C}=\frac{1}{1-\tilde{\theta}_{C}}$, while the median member's preference parameter is $\frac{1+\tilde{\theta}_{C}}{2}$. Substituting the median member's preference parameter and the profit share in (25) gives

$$
e^{\prime}\left(q_{C}\right)=\frac{1}{4}-\frac{p_{0}^{2}}{4\left(q_{C}-q_{0}\right)^{2}}+\frac{\tilde{\theta}_{C}\left(1-\tilde{\theta}_{C}\right)}{2} .
$$

Next, we use the fact that every consumer who is eligible to join the cooperative will do so as, due to our assumption in (5), he expects a positive dividend. Therefore, since membership depends on consumption of the good, the marginal member of a cooperative will also be its marginal consumer, formally

$$
\tilde{\theta}_{C}=\hat{\theta}_{C}^{*}=\frac{1}{2}-\frac{p_{0}}{2\left(q_{C}-q_{0}\right)}
$$

where the last part follows from (8). Inserting (27) into (26) results in $q_{C}^{*}$ as defined in the proposition.

Finally, second-order conditions require

$$
S O C_{C} \equiv \frac{1}{1-\tilde{\theta}_{C}}\left(\frac{p_{0}^{2}}{2\left(q_{C}^{*}-q_{0}\right)^{3}}-e^{\prime \prime}\left(q_{C}^{*}\right)\right)<0
$$

to hold, again with $\tilde{\theta}_{C}=\hat{\theta}_{C}^{*}$.

(ii) follows from the individually optimal quality as specified in (25). Q.E.D. 


\section{A.5 Proof of Proposition 1}

The results are based on the convexity assumption in (2): $q_{C}^{*}>q_{F}^{*}$ follows from $q_{0}+p_{0}<q_{j}$ and hence $\frac{p_{0}}{q_{j}-q_{0}}<1$ for $j \in\{F, C, N\} ; q_{N}^{*} \geq q_{S B}$ by assumption (4); $q_{S B}>q_{C}^{*}$ for $p_{0}>0$ and $q_{S B}=q_{C}^{*}$ for $p_{0}=0$.

\section{A.6 Proof of Proposition 2}

Generally, the difference in total surplus between two organizations $j, k \in\{F, N, C\}$, $k \neq j$ is

$$
\begin{aligned}
T S_{j}-T S_{k}= & \frac{3}{8}\left(q_{j}^{*}-q_{k}^{*}\right)-\left(e\left(q_{j}^{*}\right)-e\left(q_{k}^{*}\right)\right) \\
& +\frac{p_{0}^{2}\left(q_{j}^{*}-q_{k}^{*}\right)}{8\left(q_{j}^{*}-q_{0}\right)\left(q_{k}^{*}-q_{0}\right)}-D\left(I_{j}-I_{k}\right)
\end{aligned}
$$

(i): The difference between total surplus under nonprofit and under firm organization is $T S_{N}-T S_{F}=\frac{3}{8}\left(q_{N}^{*}-q_{F}^{*}\right)-\left(e\left(q_{N}^{*}\right)-e\left(q_{F}^{*}\right)\right)+\frac{p_{0}^{2}\left(q_{N}^{*}-q_{F}^{*}\right)}{8\left(q_{N}^{*}-q_{0}\right)\left(q_{F}^{*}-q_{0}\right)}-D$. Solving $T S_{N}-T S_{F} \geq 0$ for $D$ yields condition (18) for superiority of the nonprofit organization.

(ii): The same is true analogously for $T S_{C}-T S_{F}$, which provides condition (19) for cooperatives to provide total surplus at least as high as firms. To see that $\bar{D}_{C F} \geq 0$, note that, by the general definition of convexity, the maximum value of $\frac{e\left(q_{C}^{*}\right)-\bar{e}\left(q_{F}^{*}\right)}{q_{C}^{*}-q_{F}^{*}}$ is $e^{\prime}\left(q_{C}^{*}\right)=\frac{3}{8}-\frac{3 p_{0}^{2}}{8\left(q_{C}^{*}-q_{0}\right)^{2}}$ (see lemma 3$)$. Inserting this into the definition of $\bar{D}_{C F}$ provides

$$
\bar{D}_{C F} \geq \frac{p_{0}^{2}}{8\left(q_{C}^{*}-q_{0}\right)\left(q_{F}^{*}-q_{0}\right)}+\frac{3 p_{0}^{2}}{8\left(q_{C}^{*}-q_{0}\right)^{2}} \geq 0
$$

Hence, for $p_{0}>0$ and $D$ sufficiently low, cooperatives are always more efficient than firms.

(iii): $T S_{N}-T S_{C} \geq 0$ provides condition (20) for cooperatives to generate higher total surplus than nonprofits.

Q.E.D.

\section{A.7 Proof of Lemma 4}

(i): $q_{N}^{*}$ is independent of any parameter changes as long as its level, $q_{N}^{*}=1$, can be financed by operational profits. This is satisfied by assumption (5).

(ii): Total differentiation of the first-order condition (FOC) of the firm (22) and use of the second-order condition, $S O C_{F}<0$, yields

$$
\frac{d q_{F}^{*}}{d p_{0}}=\frac{p_{0}}{2\left(q_{F}^{*}-q_{0}\right)^{2}\left(S O C_{F}\right)} \leq 0
$$


(iii): Total differentiation of the FOC of the cooperative (26) yields

$$
\frac{d q_{C}^{*}}{d p_{0}}=\frac{1}{\left(1-\tilde{\theta}_{C}\right) S O C_{C}}\left[\frac{p_{0}}{2\left(q_{C}^{*}-q_{0}\right)^{2}}-\frac{1-2 \tilde{\theta}_{C}}{2} \frac{d \tilde{\theta}_{C}}{d p_{0}}\right] \leq 0
$$

To see the sign of $\frac{d q_{C}^{*}}{d p_{0}}$, note that: $S O C_{C}<0$ due to the second-order condition in lemma $3 ; \tilde{\theta}_{C}=\hat{\theta}_{C}$, which implies $\tilde{\theta}_{C} \leq 1 / 2$ as well as $\frac{d \tilde{\theta}_{C}}{d p_{0}}=\frac{d \hat{\theta}_{C}}{d p_{0}}=-\frac{1}{2\left(q_{C}^{*}-q_{0}\right)}<0$ by $(8)$.

Q.E.D.

Remark: Total differentiation of the FOC of the firm (22) with respect to the quality equivalent $q_{0}$ of the substitute good yields

$$
\frac{d q_{F}^{*}}{d q_{0}}=\frac{p_{0}^{2}}{2\left(q_{F}-q_{0}\right)^{3}\left(S O C_{F}\right)} \leq 0 .
$$

For the cooperative, the comparative static is

$$
\frac{d q_{C}^{*}}{d q_{0}}=\frac{1}{\left(1-\tilde{\theta}_{C}\right) S O C_{C}}\left[\frac{p_{0}^{2}}{2\left(q_{C}-q_{0}\right)^{3}}-\frac{1-2 \tilde{\theta}_{C}}{2} \frac{d \tilde{\theta}_{C}}{d q_{0}}\right] \leq 0
$$

where the sign follows from $S O C_{C}<0$ and $\frac{d \tilde{\theta}_{C}}{d q_{0}}=\frac{d \hat{\theta}_{C}}{d q_{0}}=-\frac{p_{0}}{2\left(q_{C}^{*}-q_{0}\right)^{2}} \leq 0$. The quality level of the nonprofit remains unaffected by $q_{0}$.

\section{A.8 Proof of Lemma 5}

(i) and (ii) follow directly from lemma 4.

(iii): Using $S O C_{F}, S O C_{C}, \tilde{\theta}_{C}=\hat{\theta}_{C}$ and $\frac{d \tilde{\theta}_{C}}{d p_{0}}=-\frac{1}{2\left(q_{C}^{*}-q_{0}\right)}$ yields

$$
\frac{d q_{C}^{*}}{d p_{0}}-\frac{d q_{F}^{*}}{d p_{0}}=\frac{1.5 p_{0}\left(q_{C}^{*}-q_{0}\right)}{p_{0}^{2}-2 e^{\prime \prime}\left(q_{C}^{*}\right)\left(q_{C}^{*}-q_{0}\right)^{3}}-\frac{p_{0}\left(q_{F}^{*}-q_{0}\right)}{p_{0}^{2}-2 e^{\prime \prime}\left(q_{F}^{*}\right)\left(q_{F}^{*}-q_{0}\right)^{3}}
$$

The sign of this difference depends on the specific model parameters (both numerators are positive, with the first being larger, both denominators are negative, with the second being closer to zero). Generally, (35) is (weakly) positive iff

$$
2 e^{\prime \prime}\left(q_{C}^{*}\right)\left(q_{C}^{*}-q_{0}\right)^{2}-3 e^{\prime \prime}\left(q_{F}^{*}\right)\left(q_{F}^{*}-q_{0}\right)^{2} \geq-p_{0}^{2} \frac{q_{C}^{*}-q_{F}^{*}+0.5\left(q_{C}^{*}-q_{0}\right)}{\left(q_{C}^{*}-q_{0}\right)\left(q_{F}^{*}-q_{0}\right)}
$$

The RHS of (36) is always negative because of Proposition 1. The sign of the LHS however depends on the shape of the effort cost function.

Q.E.D. 


\section{A.9 Proof of Proposition 3}

Generally, the derivative of difference in total surplus (see (29) with respect to $p_{0}$ is

$$
\begin{aligned}
\frac{d\left(T S_{j}-T S_{k}\right)}{d p_{0}}= & \left(\frac{3}{8}-e^{\prime}\left(q_{j}^{*}\right)\right) \frac{d q_{j}^{*}}{d p_{0}}-\left(\frac{3}{8}-e^{\prime}\left(q_{k}^{*}\right)\right) \frac{d q_{k}^{*}}{d p_{0}} \\
& +\frac{p_{0}\left(q_{j}^{*}-q_{k}^{*}\right)}{4\left(q_{j}^{*}-q_{0}\right)\left(q_{k}^{*}-q_{0}\right)} \\
& +\frac{p_{0}^{2}}{8\left(q_{j}^{*}-q_{0}\right)\left(q_{k}^{*}-q_{0}\right)}\left(\frac{q_{k}^{*}-q_{0}}{q_{j}^{*}-q_{0}} \frac{d q_{j}^{*}}{d p_{0}}-\frac{q_{j}^{*}-q_{0}}{q_{k}^{*}-q_{0}} \frac{d q_{k}^{*}}{d p_{0}}\right)
\end{aligned}
$$

(i): For the difference $T S_{N}-T S_{F}$, note that $q_{N}^{*}>q_{F}^{*}>q_{0}, \frac{d q_{N}^{*}}{d p_{0}}=0, \frac{d q_{F}^{*}}{d p_{0}} \leq 0$ and $e^{\prime}\left(q_{F}^{*}\right) \leq \frac{1}{4}$ (see firm's FOC $(22)$ ). Hence, by (37),

$$
\frac{d\left(T S_{N}-T S_{F}\right)}{d p_{0}} \geq 0
$$

(ii): For the difference $T S_{N}-T S_{C}$, note that $q_{N}^{*}>q_{C}^{*}>q_{0}, \frac{d q_{N}^{*}}{d p_{0}}=0, \frac{d q_{C}^{*}}{d p_{0}} \leq 0$ and $e^{\prime}\left(q_{C}^{*}\right) \leq \frac{3}{8}$ (see the cooperative's FOC (26) where $\left.\tilde{\theta}_{C} \leq 1 / 2\right)$. Hence, by (37),

$$
\frac{d\left(T S_{N}-T S_{C}\right)}{d p_{0}} \geq 0
$$

(iii): For the difference $T S_{C}-T S_{F}$, inserting $e^{\prime}\left(q_{F}^{*}\right)$ and $e^{\prime}\left(q_{C}^{*}\right)$ from the firm's and cooperative's FOC into (37) yields, after rearranging,

$$
\begin{aligned}
\frac{d\left(T S_{C}-T S_{F}\right)}{d p_{0}}= & \left(\frac{1}{8}+\frac{3 p_{0}^{2}}{8\left(q_{F}^{*}-q_{0}\right)^{2}}\right)\left(\frac{d q_{C}^{*}}{d p_{0}}-\frac{d q_{F}^{*}}{d p_{0}}\right)+\frac{p_{0}\left(q_{C}^{*}-q_{F}^{*}\right)}{4\left(q_{F}^{*}-q_{0}\right)\left(q_{C}^{*}-q_{0}\right)} \\
& -\left(\frac{\tilde{\theta}_{C}\left(1-\tilde{\theta}_{C}\right)}{2}+\frac{\left(q_{C}^{*}-q_{0}\right)^{2}-\left(q_{F}^{*}-q_{0}\right)^{2}}{\left(q_{F}^{*}-q_{0}\right)^{2}\left(q_{C}^{*}-q_{0}\right)^{2}}\right) \frac{d q_{C}^{*}}{d p_{0}}
\end{aligned}
$$

Apart from the first term, all expressions in (40) are weakly positive. Hence, for the whole expression to be (weakly) positive, $\frac{d q_{C}^{*}}{d p_{0}}-\frac{d q_{F}^{*}}{d p_{0}} \geq 0$ is a sufficient condition. Lemma 5.(iii) provides the conditions for the latter inequality to hold. Q.E.D. Remark: Generally, the derivative of excess surplus with respect to $q_{0}$ yields

$$
\begin{aligned}
\frac{d\left(T S_{j}-T S_{k}\right)}{d q_{0}}= & \left(\frac{3}{8}-e^{\prime}\left(q_{j}^{*}\right)\right) \frac{d q_{j}^{*}}{d q_{0}}-\left(\frac{3}{8}-e^{\prime}\left(q_{k}^{*}\right)\right) \frac{d q_{k}^{*}}{d q_{0}} \\
& +\frac{p_{0}^{2}}{8\left(q_{j}^{*}-q_{0}\right)\left(q_{k}^{*}-q_{0}\right)}\left(\frac{q_{j}^{*}-q_{k}^{*}}{q_{k}^{*}-q_{0}}+\frac{q_{j}^{*}-q_{k}^{*}}{q_{j}^{*}-q_{0}}\right. \\
& \left.+\frac{q_{k}^{*}-q_{0}}{q_{j}^{*}-q_{0}} \frac{d q_{j}^{*}}{d q_{0}}-\frac{q_{j}^{*}-q_{0}}{q_{k}^{*}-q_{0}} \frac{d q_{k}^{*}}{d q_{0}}\right)
\end{aligned}
$$


For the difference $T S_{N}-T S_{F}$, this implies

$$
\frac{d\left(T S_{N}-T S_{F}\right)}{d q_{0}} \geq 0
$$

as $\frac{d q_{N}^{*}}{d q_{0}}=0, \frac{d q_{F}^{*}}{d q_{0}} \leq 0$ and $e^{\prime}\left(q_{F}^{*}\right) \leq \frac{1}{4}$.

For the difference $T S_{N}-T S_{C}$, this implies

$$
\frac{d\left(T S_{N}-T S_{C}\right)}{d q_{0}} \geq 0
$$

as $\frac{d q_{N}^{*}}{d q_{0}}=0, \frac{d q_{C}^{*}}{d q_{0}} \leq 0$ and $e^{\prime}\left(q_{C}^{*}\right) \leq \frac{3}{8}$.

For the difference $T S_{C}-T S_{F}$, the sign of the derivative with respect to $q_{0}$ is generally indeterminate.

\section{A.10 Numerical Example}

To illustrate the efficiency comparisons and the effects of costs of collective decision making and the curvature of the effort cost function graphically, we computed the following example:

$$
e(q)=\frac{x}{4} q^{2}
$$

where $x \in[0.753 ; 0.78]$ to meet the restrictions imposed by our model. We additionally assumed $q_{0}=0.1$ and $p_{0}=0.095$ (figure 1 ) or a decrease in $p_{0}$ from 0.095 to 0.09 (figure 2). Quality levels chosen and total surplus are then calculated explicitly for each organization. Figures 1 and 2 then plot levels of $D \in[0.0232 ; 0.0242]$ along the ordinate against the convexity measure.

Remark: The results from the numerical calculations do not depend on the specific form assumed above: Similar numerical computations were undertaken for $e(q)=\frac{e^{q x}-1}{25}$ and $e(q)=\frac{1}{4} q^{1+x}$ as specific functional forms. For valid parameter ranges and different values of $x$, the same patterns emerge as those depicted in figures 1 and 2 . 